\title{
Constructive Development and Counselor Competence
}

\author{
Karen P. Eriksen \& Garrett J. McAuliffe
}

\begin{abstract}
Developmental predictors of students' ability to learn counseling skills would help counselor educators select candidates and assist admitted students in their learning. The present research examined the relationship between adult development, as measured by the Learning Environment Preferences test (W. S. Moore, 1989) and the Defining Issues Test (J. Rest, D. Narvaez, M. J. Bebeau, \& S. J. Thoma, 1999), and counseling skills performance, as rated by faculty experts using the Counseling Skills Scale (K. P. Eriksen \& G. J. McAuliffe, 2003). Data indicate that adult moral development contributed to $18 \%$ of the variance in students' counseling skills performance.
\end{abstract}

The search for student characteristics that might predict students' ability to become effective counselors has varied in focus and in promise. Personality trait research has dominated this area of inquiry (e.g., Aberra, 2000; Lambert \& Bergin, 1983; Osipow \& Walsh, 1973). Despite many efforts, as Zinn (1996) noted in his review, results of such research are inconclusive.

The usual means of predicting student success are admissions criteria, which predominantly include undergraduate grades, Graduate Record Examination (GRE) scores, and perhaps an autobiographical essay. However, research has demonstrated repeatedly the ineffectiveness of undergraduate grades and admissions examinations in predicting counselor trainees' development of effective counseling skills; rather, such admissions criteria predict only graduate grades, and those grades can be predicted only to a limited degree (Aberra, 2000; Weaver, 2000).

The personal characteristics of the counselor have been demonstrated to contribute to counseling outcomes more so than the use of any particular techniques (Wampold, 2001). For instance, counseling program admittees who demonstrate empathy, tolerance, a sense of well-being, social intelligence, self-esteem, and psychological mindedness are more likely to become effective counselors (Aberra, 2000; Osipow \& Walsh, 1973; Weaver, 2000). It is imperative for counselor educators to discover and nurture those characteristics that might be necessary both to learn and to practice good counseling. Our research explores the degree to which students' adult development levels predict their ability to develop counseling skills.

Karen P. Eriksen, Department of Counseling, California State University, Fullerton; Garrett J. McAuliffe, Department of Counseling, Old Dominion University. This research was partially funded by a grant from Radford University and the Association for Counselor Education and Supervision. Correspondence concerning this article should be addressed to Karen P. Eriksen, 148 Pineview, Irvine, CA 92620 (e-mail: kareneriksen@cox.net). 


\section{Developmental Theory: An Alternative Predictor}

Constructive developmental theory translates the previously mentioned traits (e.g., empathy, tolerance, and self-esteem) into a more dynamic and inclusive formulation of human capacity. Thus, the more global assessments required by constructive development theory regarding developmental capacity might allow counselor educators to measure students' personal characteristics more comprehensively. In fact, the idea of incorporating separate characteristics into an overall evolving personality structure that influences how a person makes meaning was the initial reason for establishing constructive developmental theory (Belenky, Clinchy, Goldberger, \& Tarule, 1986; Borders \& Fong, 1989; Kegan, 1982, 1994; Loevinger, 1976).

Another advantage of the developmental approach to human assessment, in contrast to the trait approach, is that it allows for the view that a student's development is an evolving process and one that is amenable to intervention (Kegan, 1982). In fact, methods of developmental instruction have been presented (e.g., Bebeau \& Brabeck, 1987; Kohlberg \& Mayer, 1972; Sprinthall, 1994). The application of such intentional developmental strategies to counselor education has been proposed (e.g., Haag-Granello \& Hazler, 1998; Paisley \& Benshoff, 1998). Thus, rather than using developmental assessment to merely "weed out" certain students at admission, developmental theory offers the means to promote students' development during the training program and thus, theoretically at least, the possibility to improve students' capacity to become effective counselors.

\section{Developmental Theories}

The developmental trend is grounded in the neo-Piagetian theories of the evolution of meaning making (Kegan, 1982). Since 1970 or so, developmental literature has included research that more substantially extended Piagetian-style theories to adulthood (e.g., Belenky et al., 1986; Kegan, 1982, 1994; Kohlberg, 1984; Loevinger, 1976; Perry, 1999). Developmentalists plot systematic progression in the moral, ego, and epistemological domains, following Piaget's "genetic epistemology" tradition (e.g., Piaget, 1954). This structural notion of development refers to how, rather than what, a person knows; it attends to the methods and sources rather than to the content of a person's knowing. In developmental theory, such characteristics as dogmatism, autonomy, conformism, rigidity, and their counterparts have emerged not as isolated traits but as dimensions of a person's overall evolving ways of knowing. Thus, developmental theory guides the educator to focus on those aspects of the individual that are in process and that may, therefore, be developed.

Two developmental schemes of adult meaning making that offer possibilities for research and practice are Perry's (1999) theory of intellectual and ethical development and Kohlberg's (1984) theory of moral development. These two theories describe in parallel fashion 
the movement of meaning making from external, simpler ways of experiencing through relativistic and dialectical engagements (e.g., Kurfiss, 1988). The global term constructive development has sometimes been applied to all descriptions of individual evolution of meaning making (e.g., Borders, Fong, \& Neimeyer, 1986). We also use that inclusive term in this article.

\section{Perry's Scheme of Intellectual Development}

Perry's (1999) scheme of intellectual and ethical development has been explored in relationship to counseling characteristics. On the basis of his qualitative analyses of written student evaluations of university instruction, Perry proposed that adults can be placed along a continuum of nine epistemological positions. The evolving capacities associated with these positions have led them to be called stages in the constructive developmental literature. A person's epistemological capacity can range from a more rigid or authoritarian (external) inclination to a flexible and self-authorized (internal) epistemology. Perry called the more rigid and external orientation dualism. He named the more flexible and internal position relativism. These positions have some malleability; that is, although individuals seem to be inclined toward one position, they can sometimes use reasoning from earlier positions, as well as comprehend one position beyond their own.

Strong relationships have been reported between Perry's (1999) positions, as measured by the Learning Environment Preferences test (LEP; Moore, 1989), and traits demonstrated to be associated with counseling ability. For instance, higher Perry levels are associated with higher levels of empathy (Benack, 1988; Lovell, 1999), internality, and open-mindedness (Neukrug \& McAuliffe, 1993). A recent qualitative study (McAuliffe, 2002) found that relativistic counseling students were more able than dualists to tolerate ambiguity, be reflective, use evidence for choices, be empathic, and demonstrate insight into clients' issues. What is still absent from research, however, is an empirical demonstration of the constructive development/counseling skills connection, using the LEP to measure constructive development.

\section{Kohlberg's Moral Development Theory}

Kohlberg's (1984) moral development theory has also begun to be applied to counselor education and supervision. Kohlberg's theory poses a set of stages of development in both the moral and intellectual domains, ranging from thinking that relies on external consequences for moral action to thinking that is more internally principled. Rest, Narvaez, Bebeau, and Thoma (1999) developed the Defining Issues Test (DIT) to assess Kohlbergian levels of moral judgment. The DIT focuses only on three stages of moral development because the test was unable to discriminate all six of Kohlberg's stages; the stages are personal self-interest, maintaining norms (roughly equivalent to Kohlberg's preconventional and conventional levels), and postconventional thinking. 
A small number of studies examined moral development in counseling students. In one of the earlier studies that used the DIT, master'slevel counseling students were generally found to be at conventional (reliant on social norms) or lower levels (White, 1979). Thus, their ability to question norms and refer to principles seemed questionable.

Beginning at such levels (i.e., conventional or lower levels), however, did not have to be ultimately limiting; that is, counselor education was able to affect moral development, according to Bernier (1980). In his study of counseling students in a counseling skills course, Bernier found that the students showed gains in moral development from pretest to posttest.

Moral development and empathy have also been shown to be associated, as might be expected. Bowman and Reeves (1987) found moral development to be significantly related to the ability to empathize. More recent findings in this area have been less clear, although the trend continues to support increases in moral development as a result of participation in counselor education programs (Lovell, 1999; McAuliffe \& Lovell, in press). However, the importance of this trend is only suggestive because there have been no studies of the relationship between moral development and the more inclusive notion of overall counseling skills performance.

\section{Developmental Levels and Counseling Skills: Current Status}

Although promising, studies of the relationship between constructive development and counseling skills have resulted in equivocal findings. One counselor characteristic, empathy, has been strongly associated with development, whether that development is ego, intellectual, or moral (e.g., Bowman \& Reeves, 1987; Carlozzi, Gaa, \& Lieberman, 1983; Lovell, 1999). However, no strong trend connects development and overall potential for becoming an effective counselor. On the basis of research, therefore, it seems premature to suggest that counselor education become "developmental," as a number of authors have proposed (e.g., Haag-Granello \& Hazler, 1998; Paisley \& Benshoff, 1998). Explicit empirical evidence for the developmental level/counseling skills relationship will be required if professionals in the field are to work confidently to promote students' constructive developmental capacities.

\section{Problems in the Measurement of Counseling Ability}

The inadequacies of the procedures used to measure counseling abilities are another problem in this line of research. With one exception, the Counseling Skills Scale (CSS; Eriksen \& McAuliffe, 2003), the following limitations characterize these procedures throughout the research: indirect assessment of counseling ability, use of nonvalidated instruments, limitations in the range of counseling skills assessed, and limited qualifications of some of the raters.

Indirect assessment of counseling ability occurred in studies that compared students' developmental levels with their conceptualizations 
of clients (Borders et al., 1986); their essays on the client's experience (Benack, 1988); and their responses to empathy, dogmatism, and externality measures (Neukrug \& McAuliffe, 1993). The nonvalidated instruments used in research included (a) a global scale ranging from "damaging" to "accurate" for the first eight counselor responses in an interview (Borders \& Fong, 1989), (b) the Counseling Effectiveness Rating Scale (Zinn, 1996), (c) an author-created measure of six counseling functions (Benack, 1988), and (d) an inductive analysis of student interviews (McAuliffe, 2002). The limited range of counseling skills measured was observed in research that examined only empathy as a dependent variable (e.g., Benack, 1988; Lovell, 1999). Finally, an additional validity limitation lay in the use of graduate students to rate counselor interviews, often without reference to the students' qualifications to do such ratings (e.g., Benack, 1988; Borders \& Fong, 1989; McAuliffe, 2002). We believe that instructors, as the gatekeepers of the profession, should do the rating and that they should use a validated instrument to do so. The current research attempts to address these limitations by having faculty use a direct, validated, and comprehensive measure of counseling skills, specifically, the CSS.

\section{Method}

This correlational research attempts to answer the question, "To what degree do students' adult development levels, as defined by scores on the LEP and the DIT, predict their abilities to learn counseling skills, as defined by scores on the CSS?" Assessment of students occurred in the counseling skills course during the 1st week of the initial semester of students' graduate training. Prior to the beginning of instruction, students in the counseling skills course completed an assignment suggested by Ivey and Ivey (1999). They paired up with a classmate or friend and conducted a 10-minute, videotaped "session" in which they demonstrated their natural ways of helping. The course instructors, who were trained raters, evaluated these pretest videotapes, using the CSS. At the end of the counseling skills course, the same faculty members evaluated the students' final 30-minute posttest counseling videotapes. The raters did not have access to the pretest scores once they had completed the initial ratings.

Training for raters included review of the CSS and its development, practice rating student videotapes, and discussion on correct ratings following trainees' independent ratings. Interrater reliability was established during the initial training of five counselor educators from two universities; the raters had varying levels of experience. Interrater reliability reached .768 correspondence in final ratings of videotapes during training (Eriksen \& McAuliffe, 2003).

During the 1st week of class, students also completed a brief demographic survey (age, sex, counseling specialty, full-time or part-time student, religious orientation, undergraduate major, race, and political orientation); permission forms to participate in the 
research; and two measures of adult development-the LEP, as a measure of ethical and intellectual development, and the DIT, as a measure of Kohlberg's (1984) stages of moral development.

\section{Instruments}

CSS. The CSS, which measures counseling skills performance, consists of 19 items and six subscales on which trained raters evaluate students on a Likert-type scale from -2 (major adjustment needed) to +2 (highly developed skills). Item scores are averaged into subscale scores, which are then added to become a total counseling skills score. The items reflect microskills that are included in most counseling skills textbooks. Body language, minimal encouragers, vocal tone, and evoking and punctuating strengths are grouped into a subscale titled Shows Interest and Appreciation. Questioning, requesting concrete and specific examples, paraphrasing, and summarizing are grouped into a subscale called Encourages Exploration. Reflecting feelings, using immediacy, observing themes and patterns, challenging/pointing out discrepancies, and reflecting meaning and values are included in the subscale called Deepens the Session. Determining goals/outcomes, creating change, considering alternatives, and planning action/anticipating obstacles constitute the subscale Encourages Change. The two final subscales are Develops Therapeutic Relationship and Manages the Session. Initial construct validation research indicated significant differences in means between students' scores prior to and after taking the counseling skills course (difference in means $=3.03, t=5.6, p<$ .000), with an effect size of .93. Cronbach's alpha indicated an internal consistency of .90 (Eriksen, 2005).

LEP. The LEP measures constructive developmental positions by asking students to rate their preference on each of 65 items across five domains of how they prefer to learn. The items range from those indicating a strong reliance on external authority (dualism) to preference for dialogue and discovery (relativism). Participants rate each item on a 5-point Likert-type scale from not at all significant to very significant. The resulting raw scores are then processed to produce a cognitive complexity index (CCI) and four position preference scores that correspond to Perry (1999) Positions 2 to 5 (Moore, 1989). In this study, the CCI, because it offers interval data, was (a) correlated with counseling skills scores, (b) included in the multiple regression analysis, and (c) used to determine what positions students primarily preferred. Because it is possible to tell position preference from the CCI and because the ordinal data of the position preference scores would offer less statistical strength to the research, we did not consider it necessary to use the position preference scores.

The internal consistency of the LEP has been tested through calculation of Cronbach's alpha. The alphas range from .72 to .84 for each position across all five domains. Test-retest reliability can be as high as .89 (Moore, 1989). Construct validity for the LEP is 
indicated by Moore's finding of upward hierarchical progression from Positions 2 to 5 and by his discovery of strong correlations between Perry (1999) positions and other related constructs. The LEP shows a correlation of .36 with the Measure of Intellectual Development (Knefelkamp \& Cornfeld, 1978), a parallel measure of the Perry scheme.

DIT. The DIT was developed to measure Kohlberg's (1984) stages of moral development. It presents a hypothetical dilemma that is followed by 12 items that respondents rate and rank in terms of their importance. The scores represent the degree to which a respondent uses personal interest, maintaining norms, or postconventional schemas in making moral judgments. Studies show (a) differentiation of various age/education groups; (b) longitudinal gains (effect size $=.80$ ); $(\mathrm{c})$ relationships to cognitive capacity measures of moral comprehension $(r=.60 \mathrm{~s})$, recall, and reconstruction of postconventional moral arguments, and Kohlberg's interview measure; (d) sensitivity to moral education interventions (effect size $=.41$ ); (e) significant links to many prosocial behaviors and to desired professional decision making; (f) significant links to political attitudes and political choices ( $r=.40$ to .65); and (g) adequate reliability (Cronbach's alpha and test-retest reliability, upper $.70 \mathrm{~s}$ and low .80s).

\section{Sample}

The entire population $(N=119)$ of graduate counselor education students in counseling skills courses at three universities in various parts of the United States was assessed over a 4-year period. The universities were (a) a small, rural, teaching university in a mid-Atlantic state; (b) a large urban, state research university in a mid-Atlantic state; and (c) a suburban professional school in a western state. Students' ages ranged from 21 to 58 years, with a mean age of 30. Eighty-two percent $(n=97)$ were women and $18 \%(n=22)$ were men. Sixty-six percent $(n=79)$ were White/European American/ non-Hispanic, $14 \%(n=17)$ were African American, 9\% $(n=11)$ were Latino/a, $5 \%(n=6)$ were Asian American, and 5\% $(n=6$; percentages do not equal 100\% because of rounding) reported "other" as their ethnic background. There were no Native American students.

\section{Results}

Descriptive statistics were computed on CSS scores and adult development scores. CSS total scores ranged from -9.83 to 12 , with a mean of $5.56(S D=4.28)$. DIT-N2 scores ranged from 2.41 to 75.27 , with a mean of $31.81(S D=18.91)$. This means that students generally used conventional or norm-maintaining means of considering moral issues. LEP scores ranged from 246 to 429, with a mean of $360(S D=50.21)$, thereby placing students, on average, between Perry's (1999) positions of multiplicity and early relativism. This finding indicates that the students recognized that there are multiple "truths" but that they were not yet able to carefully weigh the perspectives according to some internal standard. 
Stepwise multiple regression, including all variables, indicated that only the DIT-N2 score and the DIT-P scores (two different methods of computing DIT scores) contributed significantly to the CSS scores (for the DIT-N2, $r=.423, p<.001, r^{2}=.18$; for the DIT-P, $r=$ $\left..402, p<.002, r^{2}=.16\right)$. Therefore, moral development, as measured by the DIT, contributed $16 \%$ to $18 \%$ of the variance in participants' counseling skills scores.

\section{Discussion}

The purpose of the research was to determine the degree to which the developmental level of entering counseling students contributes to their ability to learn counseling skills. Moral reasoning ability, as measured by the DIT, showed a significant relationship to students' ability to learn counseling skills, contributing up to $18 \%$ of the variance in their counseling skills performance. Although a correlation of .423 indicates substantial contributions by other factors, the ability of the DIT to predict an individual's ability to learn counseling skills is reasonably high when compared with the predictive ability of the most common admissions criteria. For instance, the GRE predicts only 6\% to $9 \%$ of the variance in 1st-year graduate students' grades in all fields. Undergraduate grades predict graduate grades somewhat better, accounting for $14 \%$ of the variance (FairTest, 2001). The DIT, therefore, shows promise as a selection and readiness assessment tool for potential counselors.

\section{The LEP}

The absence of an LEP/CSS relationship was surprising, because it contradicts the important constructive developmentempathy relationships that were found previously using the LEP (e.g., Benack, 1988; Lovell, 1999) and the increases that have been shown in LEP scores of community counseling students during the entire course of their graduate programs (HaagGranello \& Hazler, 1998). It is possible that the broader range of counseling skills that are measured by the CSS tap into schemas that the LEP does not access. For instance, in order to obtain a cognitive complexity score, the LEP elicits students' responses to questions regarding their desires related to classroom experiences, knowledge acquisition, and relationships with instructors. Perhaps learning beginning counseling skills with "clients" who are actually peers differs substantially from the more demanding application of theory with "real" clients, who may be very different from the student. The initial learning experience emphasizes "being with" peers in increasingly deeper ways and may thus tap into students' emotional and relational selves more than into their cognitive selves. Planned longitudinal studies may offer a clearer understanding of the fit between the schemas measured by the LEP and students' counseling capacities. 


\section{The DIT}

What might be the explanation for the DIT/CSS connection? The DIT measures the degree to which people operate from a postconventional thinking schema. Movement on the DIT indicates progression from a personal interest orientation through a maintaining norms orientation to postconventional thinking. As noted in this and previous research, counseling students tend to operate out of the maintaining norms schema. Such people consider it important to have laws or a society-wide system of norms because they understand that people have to get along with individuals who are not their kin and friends. This conventional stance is duty oriented and responsive to hierarchical systems. Individuals who operate from this schema expect that authorities should instruct and that they should be obeyed. Morality becomes equivalent to maintaining the social order. Such morality benefits the life of a community more so than does a morality that has its base in personal interest. However, individuals who invest predominantly in maintaining the current social order will have little tolerance for, or interest in, those who differ from the dominant culture (Rest et al., 1999). This seems to fit with our experience of the need to assist counseling students to think beyond their own sphere and to adopt more multicultural perspectives.

Indeed, it seems that counselor educators aim to assist students toward a postconventional schema because it parallels the work of counseling. Postconventional people move beyond considering the current social order to be ultimate. They realize that laws, roles, and codes are social arrangements that can be set up in a variety of ways and that such norms are useful as long as they work for all members. If the rules are not working, they need to be renegotiated. The process of renegotiation appeals to an ideal that can be shared (i.e., it is not ethnocentric), that applies social norms uniformly, and that ensures that norms are not biased in favor of some at the expense of others (Rest et al., 1999). Clearly, this schema is far more conscious of diversity and is committed to ideals being applied even to individuals who do not fit within the mainstream, dominant culture.

A postconventional stance also parallels the clinical work of other health-oriented professions. A strong relationship between higher DIT scores and professional performance has been found for nurses, physicians, physical therapists, and medical interns (Rest \& Narvaez, 1994; Rest et al., 1999). Each of these professions, similar to counseling, requires judgments to be made in ill-structured situations. Counseling also requires openness to others' experience, a recognition of the emerging storying that is human experience (Winslade, Crocket, Monk, \& Drewery, 2000). A counselor must be able to suspend her or his understandings about what is normal or possible in favor of openness to emerging stories that work for the individual and for the community. Counseling thus requires respect for individualism, even idiosyncratic behavior. The work of counseling asks helpers to regularly consider norm-challenging situations and to engage in dialogue with individuals who do not 
adhere to norms. Thus, it is not surprising that individuals who receive higher postconventional scores on the DIT also receive higher scores on the CSS. A review of CSS items reveals the following expectations for the counselor: "deepens the session," "challenges discrepancies," "collaboratively determines outcomes," "identifies overarching themes and patterns . . . in problem situations," and recognizes "hereand-now feelings . . . within and between the client or the counselor" (Eriksen \& McAuliffe, 2003). Such a set of skills requires a postconventional commitment to emergent meaning construction through inner and outer dialogue (Kegan, 1982) and a tolerance for ambiguity. The automaticity of the norm-maintaining counselor cannot tolerate the ambiguity required to develop the skills measured by the CSS.

\section{Implications for Counselor Education}

If we conclude that counselors need to be more postconventional in order to be competent, what does that mean in terms of selection criteria, pedagogical strategies, and evaluation criteria in counselor education programs? If the results of this study continue to hold, that is, if counseling skill continues to be shown to be highly related to moral development, then the high percentage of normmaintaining and perhaps preconventional students challenges counselor educators either to help students to develop or to weed out students at various gatekeeping moments in the program.

As gatekeepers, counselor educators might use moral development assessment during the screening, evaluation, instructional, and graduation processes. Early and periodic assessment of developmental levels could be combined with the currently available methods for developmental and experiential instruction (e.g., Knefelkamp, 1974; Kolb, 1984; Sprinthall, 1994). Counselor educators might then intentionally promote such development as an integral part of the curriculum. As noted, such an approach has already been called for in the counselor education literature (Haag-Granello \& Hazler, 1998; McAuliffe \& Lovell, 2000). Development-promoting interventions would consist of optimally matching and mismatching students' current developmental capacities through classroom dilemma discussions and inductive experience in the field. (See Eriksen \& McAuliffe, 2001; Knefelkamp, 1974; Kolb, 1984; McAuliffe \& Eriksen, 2000, 2002; and Sprinthall, 1994, for further discussions of how this might be done.)

\section{Limitations}

Limitations of the research include biases that may have resulted from the researchers scoring some of the CSSs; attempts to limit bias included remaining unaware of constructive developmental scores until after the CSSs were scored. In addition, because the research was conducted at three universities, with seven faculty members, it was difficult to ensure that the counseling skills instruction was comparable for all students, which may have altered CSS scores, regardless of initial constructive development 
scores. Finally, further posttraining exploration of interrater reliability has left us concerned about whether CSS items are being interpreted differently by different raters, indicating that caution should be exercised in interpreting the results of the current study. This may be a concern that is common to many tests, although particularly for tests that require subjective evaluation of the rated behavior (e.g., Was the counseling skill performed sensitively, smoothly, and at an appropriate time?). In an attempt to address these concerns, we plan to develop a manual for the CSS, require continuing education for raters, and try different methods for training raters to determine the best method for achieving high interrater reliability for real-world use of the CSS.

\section{Conclusion}

Movement toward enacting a developmental counselor education requires educators to have confidence in the link between development and students' ability to demonstrate counseling skills. In this study, a link was found in the area of moral development. The ill-structured situations required by counseling seem to call on a postconventional capacity to withhold judgment, tolerate ambiguity, and empathically engage in another person's meaning making in order that clients might re-story their lives. Postconventional thinking might thus be a prerequisite or a corequisite for the work of effective counseling.

\section{References}

Aberra, T. (2000). A comparison of $16 \mathrm{PF}$ findings between high- and lowranked students in a clinical psychology graduate program. Dissertation Abstracts International, 61, 6B. (UMI No. 95024-237)

Bebeau, M. J., \& Brabeck, M. M. (1987). Integrating care and justice issues in professional moral education: A gender perspective. Journal of Moral Education, 22, 189-203.

Belenky, M., Clinchy, B., Goldberger, N., \& Tarule, J. (1986). Women's ways of knowing. New York: Basic Books.

Benack, S. (1988). Relativistic thought: A cognitive basis for empathy in counseling. Counselor Education and Supervision, 27, 216-232.

Bernier, J. (1980). Training and supervising counselors: Lessons learned from deliberate psychological education. The Personnel and Guidance Journal, 59, 15-20.

Borders, L. D., \& Fong, M. L. (1989). Ego development and counseling ability during training. Counselor Education and Supervision, 29, 71-83.

Borders, L. D., Fong, M. L., \& Neimeyer, G. J. (1986). Counseling students' level of ego development and perceptions of clients. Counselor Education and Supervision, 26, 36-49.

Bowman, J. T., \& Reeves, T. G. (1987). Moral development and empathy in counseling. Counselor Education and Supervision, 26, 293-298.

Carlozzi, A. F., Gaa, J. P., \& Lieberman, D. B. (1983). Empathy and ego development. Journal of Counseling Psychology, 30, 113-116.

Eriksen, K. P. (2005, April). Counseling Skills Scale training. A preconvention training workshop presented at the annual convention of the American Counseling Association, Atlanta, GA.

Eriksen, K. P., \& McAuliffe, G. J. (2001). Teaching counselors and therapists: Constructivist and developmental course design. Westport, CT: Bergin \& Garvey. 
Eriksen, K. P., \& McAuliffe, G. J. (2003). The Counseling Skills Scale: A measure of counselor competence. Counselor Education and Supervision, $43,120-133$.

FairTest. (2001). Examining the GRE: Myths, misuses, and alternatives. Retrieved February 11, 2002, from http://www.FairTest.org/facts/gre.htm

Haag-Granello, D., \& Hazler, R. J. (1998). A developmental rationale for curriculum order and teaching styles in counselor education programs. Counselor Education and Supervision, 38, 89-105.

Ivey, A. E., \& Ivey, M. B. (1999). Intentional interviewing and counseling. Pacific Grove, CA: Brooks/Cole.

Kegan, R. (1982). The evolving self: Problems and process in human development. Cambridge, MA: Harvard University Press.

Kegan, R. (1994). In over our heads: The mental demands of modern life. Cambridge, MA: Harvard University Press.

Knefelkamp, L. L. (1974). Developmental instruction: Fostering intellectual and personal growth in college students. Unpublished doctoral dissertation, University of Minnesota, Minneapolis.

Knefelkamp, L. L., \& Cornfeld, J. L. (1978, March). Combining student stage and style in the design of learning environments: Using Holland typologies and Perry stages. Paper presented at the annual meeting of the American College Personnel Association, Los Angeles.

Kohlberg, L. (1984). The psychology of moral development: The nature and validity of moral stages. San Francisco: Harper \& Row.

Kohlberg, L., \& Mayer, R. (1972). Development as the aim of education. Harvard Education Review, 42, 449-496.

Kolb, D. (1984). Experiential learning. Englewood Cliffs, NJ: Prentice Hall.

Kurfiss, J. G. (1988). Critical thinking: Theory, research, practice, and possibilities. Washington, DC: Association for the Study of Higher Education.

Lambert, M. J., \& Bergin, A. E. (1983). Therapist characteristics and their contribution to psychological outcome. In C. E. Walker (Ed.), The handbook of clinical psychology (Vol. 1, pp. 205-241). Homewood, IL: Dow Jones-Irvin.

Loevinger, J. (1976). Ego development. San Francisco: Jossey-Bass.

Lovell, C. W. (1999). Empathic-cognitive development in students of counseling. Journal of Adult Development, 6, 195-203.

McAuliffe, G. J. (2002, January). The impact of counselor epistemology on clinical competence: Comparing relativists' and dualists' counseling interviews. Paper presented at the meeting of the Perry Network, Fullerton, CA.

McAuliffe, G. J., \& Eriksen, K. P. (2000). Preparing counselors and therapists: Creating constructivist and developmental programs. Alexandria, VA: Association for Counselor Education and Supervision.

McAuliffe, G. J., \& Eriksen, K. P. (2002). Teaching strategies for constructivist and developmental counselor education. Westport, CT: Bergin \& Garvey.

McAuliffe, G. J., \& Lovell, C. W. (2000). Encouraging transformation: Guidelines for constructivist and developmental counselor education. In G. McAuliffe, K. Eriksen, \& Associates (Eds.), Preparing counselors and therapists: Creating constructivist and developmental programs (pp. 14-41). Alexandria, VA: Association for Counselor Education and Supervision.

McAuliffe, G. J., \& Lovell, C. W. (in press). The influence of counselor epistemology on the helping interview: A qualitative study. Journal of Counseling \& Development.

Moore, W. S. (1989). The Learning Environment Preferences: Exploring the construct validity of an objective measure of the Perry scheme of intellectual development. Journal of College Student Development, 30, 504-514.

Neukrug, E. S., \& McAuliffe, G. (1993). Cognitive development and human services education. Human Services Education, 13, 13-26.

Osipow, S. H., \& Walsh, W. B. (1973). Social intelligence and the selection of counselors. Journal of Counseling Psychology, 20, 366-369.

Paisley, P. O., \& Benshoff, J. M. (1998). A developmental focus: Implications for counsellor education. Canadian Journal of Counselling, 32, 27-36. 
Perry, W. G. (1999). Forms of intellectual and ethical development in the college years: A scheme. New York: Holt, Rinehart \& Winston.

Piaget, J. (1954). The construction of reality in the child. New York: Basic Books.

Rest, J., \& Narvaez, D. (Eds.). (1994). Moral development in the professions: Psychology and applied ethics. Hillsdale, NJ: Erlbaum.

Rest, J., Narvaez, D., Bebeau, M. J., \& Thoma, S. J. (1999). Postconventional moral thinking: A neo-Kohlbergian approach. Mahwah, NJ: Erlbaum.

Sprinthall, N. A. (1994). Counseling and social role-taking: Promoting moral and ego development. In J. Rest \& D. Narvaez (Eds.), Moral development in the professions: Psychology and applied ethics (pp. 85-100). Hillsdale, NJ: Erlbaum.

Wampold, B. E. (2001). The great psychotherapy debate. Mahwah, NJ: Erlbaum.

Weaver, K. M. (2000). The use of the California Psychological Inventory in identifying personal characteristics of effective beginning counselors. Dissertation Abstracts International, 60, 12A. (UMI No. 95011-031)

White, B. M. (1979). Beginning counselors and moral judgment. (ERIC Document Reproduction Service No. ED189504)

Winslade, J., Crocket, K., Monk, G., \& Drewery, W. (2000). The storying of professional development. In G. McAuliffe, K. Eriksen, \& Associates (Eds.), Preparing counselors and therapists: Creating constructivist and developmental programs (pp. 99-113). Alexandria, VA: Association for Counselor Education and Supervision.

Zinn, B. (1996). The relationship of ego development and the counseling effectiveness of counselor trainees. Dissertation Abstracts International, 56, $12 \mathrm{~B}$. (UMI No. 95011-161) 
Copyright of Counselor Education \& Supervision is the property of American Counseling Association and its content may not be copied or emailed to multiple sites or posted to a listserv without the copyright holder's express written permission. However, users may print, download, or email articles for individual use. 